\title{
Feline leukaemia
}

\author{
W. JARRETT \\ From the Department of Veterinary Pathology, University of Glasgow
}

Feline leukaemia is an excellent model for some aspects of the human disease which sometimes qualifies as a slow virus infection and sometimes does not. Three defining parameters of a slow infection are: the time of infection, the latent period, and the onset of the overt disease; the nature of the virus-cell interaction and the kinetics of both virus and cells at each of these times is of major importance in the understanding of the pathogenesis and immunology of leukaemia.

Consideration of the time of infection raises a major difficulty in practical terms. A fashionable theory of the moment is the ubiquitous oncogene hypothesis. Stated in its most extreme form, this proposes that oncorna viruses may be responsible for the generality of cancers (see discussion by Huebner, Todaro, Sarma, Hartleys, Freeman, Peters, Whitmire, Meier, and Gilden, 1970). An oncogene, the DNA of which is complementary to viral RNA, is integrated into the host genome and is inherited like a gene. It is normally repressed but may become derepressed by a variety of means such as irradiation, chemical carcinogens, aging, failure of immunological surveillance, etc. The genome may be wholly or partially expressed leading to production of whole virus and/or synthesis of virus-coded proteins and/or transformation to malignancy. The latter two may occur individually or together without the former.

The question may then be posed, Does a cat which subsequently develops leukaemia (1) carry the appropriate oncogene from the zygote stage, ie, true vertical transmission of the infective agent, (2) become infected from an infected parent in utero or during suckling, or (3) get infected postnatally from another infected cat, ie, true horizontal transmission?

There is now no question that the last of these three situations occurs. The original transmission experiment with cat leukaemia was attempted because I found a cluster of eight cases in a household colony of unrelated cats. Epidemiological evidence from the United States of America (Brodey, McDonough, Frye, and Hardy, 1970) indicated that the introduction of an infected tom cat into households for breeding purposes led to the establishment of infec- tion in the indigenous cats. Rickard, Post, de Noronha, and Barr (1969) found virus in a small number of control kittens housed with experimentally infected kittens. These results were suggestive, but recently we have shown in three different experiments that horizontal transmission occurs. Briefly, both young adult cats and neonates were infected with purified feline leukaemia virus (FeLV) and mixed with both littermates and unrelated cats. In one experiment, three litters were kept uninfected and maintained out of contact with the infected cats and housed in a building several miles away, out of contact with any other cats. Horizontal transmission occurred quite quickly between in-contact animals, and this was demonstrated (1) by the appearance of FeLV group-specific antigen in the circulating leucocytes of infected cats followed by a similar situation in the contact uninoculated animals; (2) by the finding of replicating FeLV in the platelets of the infected cats and later in the contact cats; (3) by the appearance of abnormal lymphocytes containing FeLV group specific (gs) antigen in some of the infected cats and later in their contacts; (4) by the raising of antibodies detected by the FOCMA (feline oncornavirus cell membrane antigen) test (Essex, Klein, Snyder, and Harrold, 1971) in both infected and control cats; (5) by the onset of leukaemia in both infected and control cats; and (6) by the demonstration of both virus and FOCMA in both groups at necropsy. The cats of the three litters which were isolated have, as yet, shown no evidence of virus infection. (This is a summary of results obtained by our own group and in collaboration with Dr Max Essex and Dr W. Hardy; these will be published.)

Secondly, what is the evidence that vertical transmission occurs? Gardner (1971) has demonstrated C-type particles in eight foetuses of three to 17 weeks gestation in six of 21 non-leukaemic dams. We have so far failed to confirm this although the numbers examined are, as yet, too small to draw conclusions. We have, however, cultured cells from many young feline embryos without finding C-type particles, infective virus or gs or FOCMA antigens in any of them. We have also carried out extensive electron microscopical and other studies in a large number of 
normal cats and have failed to find feline leukaemia virus. This may reflect different cat populations or different criteria of acceptability of EM findings. The question must, therefore, remain an open one. Furthermore, even if vertical transmission of genome does occur, its role in actual leukaemogenesis remains obscure. It is commonly assumed that exposure to viral antigens in utero renders the animal tolerant and that subsequent infection or gene derepression leads to an unopposed leukaemia. Gardner (1971) states that anti-gs antibody can only be made in a heterologous host. It has now been shown, however, that cats can produce anti-gs antibody (de Noronha, Post, Norcross, and Rickard, 1972) and it is well known that they can respond to presumed type-specific antigens of both FeLV and feline sarcoma virus (FSV) (Riggs, 1971; Essex et al, 1971 , and we have recently raised very high-titred sera in cats $(>1: 3000)$ measured by the FOCMA test.

If we now turn to the second aspect of slow virus infections, the latent period, it will be seen that here, too, considerable clarification is still needed although much is now known. I am, for the purposes of the present discussion, defining the latent period as beginning when infection has taken place and has expressed itself by virus replication proceeding in the host, ie, I am excluding the putative time interval that may occur between integration of a genome and its derepression. We have shown that when cats are inoculated neonatally with FeLV, probably every animal becomes infected (Mackey, Jarrett, Jarrett, and Laird, 1972); viral replication can be detected in platelets or in bone marrow within a month and fairly large quantities of virus are produced. Megakaryocytes replicate virus, which is reflected in blood platelet infection, and bone marrow and blood cells of the myeloid series show the presence of gs antigen in their cytoplasm by fluorescence. However, most of these animals never show malignancy of the myeloid series. Later, medium or large lymphocytes containing large amounts of gs antigen, as judged by fluorescence, appear and in our limited experience, this is prodromal to the onset of overt lymphoid malignancy. However, the latent period varies widely even between littermates given the same dose of the same purified virus. This has been seen in several of our long-term experiments and one such is illustrated in Fig. 1, in which cats developed neoplasia at ages ranging from 1 month to $3 \frac{1}{2}$ years. The experiment has now been running for about four years and it will be seen that the cumulative frequency appears linear with time although all of the animals are known to be replicating virus. What, then, is the essential leukaemogenic event? This is unknown at the moment, but there are several interesting findings

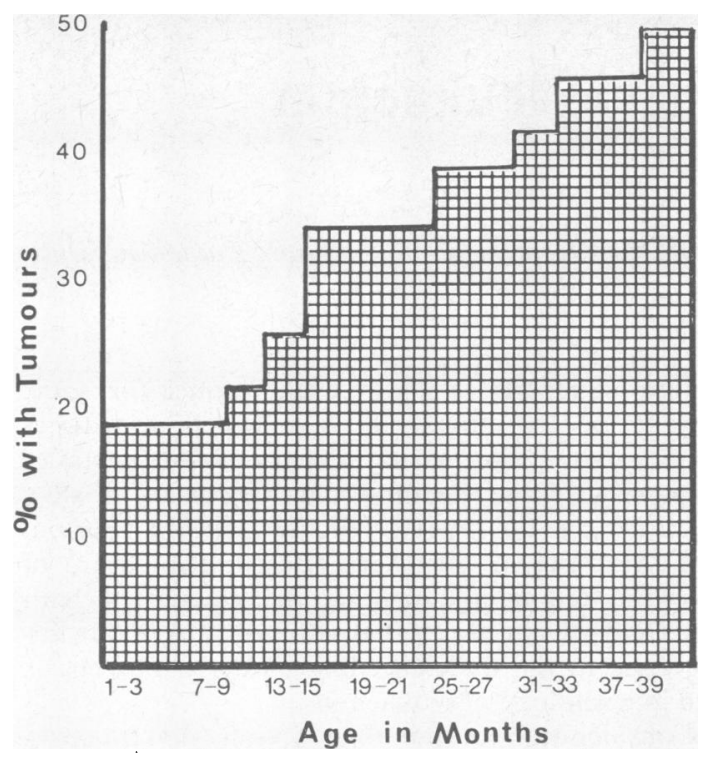

Fig. Cumulative frequency of tumour incidence (reproduced by kind permission of the Editor of the Journal of the National Cancer Institute).

and possibilities. It would not appear to be a simple dose-response relationship with the range of latent periods being a reflection of normally distributed biological variation.

If we look at the morphological findings in cat lymphoid neoplasia, several apposite facts emerge. (1) Feline lymphoid tumours occur in four distinct morphological forms, viz, thymic, alimentary, and multicentric lymphosarcoma and true leukaemia. Evidence has been presented by us suggesting that the development of these individual diseases is related to the location and population expansion of the tumour cells in specific compartments of the immunocyte system, ie, they may be diseases of the primary and secondary lymphoid traffic pathways now well recognized in immunology (Jarrett, Mackey, Jarrett, and Laird, 1972; Mackey et al, 1972; Mackey and Jarrett, 1972). (2) Again, each type falls into one of five cytological classes. We therefore have 20 possible variants of the disease. (3) It is of interest that in the great majority of cases, only one form is seen in one animal. (4) This is despite the fact that virus is known to have been replicating in several different types of haematopietic cell for periods up to four years.

This might suggest the possibility that the malignancy may be monoclonal and that transformation to overt malignancy may be an event subse- 
quent to virus infection or that infection of lymphocytes has an extremely low probability. We are, at present, attempting to investigate the first hypothesis by examining malignant cells for surface immunoglobulins and determinants. If all cells of a given malignant complex were to have a single immunoglobulinclass or subclass, it would strengthen the monoclonal theory of origin. It should be noted that the duration of the overt disease is not significantly different in an animal showing neoplasia a few months after infection from that in one where the disease occurs after a much longer period.

The possibility should also be considered that an infected haemopoietic cell may need to be subjected to the appropriate antigenic or homeostatic stimulus to produce its population expansion. We have found in the cat that multicentric lymphosarcoma shows population expansion in the thymus-dependent areas of lymph nodes, alimentary tumours in the germinal centres of lymph nodes, and true leukaemias in the haemic compartments of the lymphoid system. This might indicate a failure of feed-back control of virus-infected lymphocytes.

Little is known, at the moment, of the immunological control of leukaemia in the cat. Circulating antibodies to FOCMA are found in a proportion of both normal and leukaemic cats; in a random sample of normal cat sera, we found nine of 28 to be positive and of 19 field cases, eight were positive (this is part of a collaborative study with $\mathrm{Dr} \mathrm{M}$. Essex). It has been shown that the antibody titre in animals infected with a closely related virus, FeSV, is correlated with a regression or progression of the tumour (Essex et al, 1971). Similar data are not yet available for feline leukaemia virus. However, we have produced very high titres of antibody in cats infected with leukaemia virus and we are currently observing the response of animals to infection in terms of persistence of virus infection and status with regard to progression to malignancy.

It is of particular interest and possible relevance to the human disease that virus-coded antigens can be found in circulating granulocytes long before the overt disease develops and that preliminary results suggest that the appearance of antigen in medium and large lymphocytes heralds the onset of clinical disease. We have found that not only is the feline virus group specific antigen demonstrable in these cells by fluorescence, but the interspecies gs antigen is also present. It would appear worthwhile testing for gs antigen in the human subject to see if this antigen, which appears to be common to all of the mammalian leukaemia viruses, is expressed in leukaemic or preleukaemic states.
In summary, cats be infected horizontally by leukaemogenic virus; they might also be infected vertically, but this has not yet been proven. Virus replication or antigen production is demonstrable a short time after infection and may continue for years. The latent period varies from a few weeks to years and the factors associated with the induction of overt leukaemia are not yet known. There is at least a possibility of monoclonal origin and the disease in most cases is restricted to one compartment of the immunocyte system. The relationship of tolerance of virus antigens to the development of malignancy is not yet clarified and cats can produce antibodies to both group and type specific antigens of the virus. Adult, immunologically competent, cats can be infected artificially or horizontally with virus, can replicate virus for at least a period, and can develop leukaemia from such an infection.

The group involved in these experiments includes Christine Allen, D. Hay, O. Jarrett, W. Jarrett, Helen M. Laird and Lindsay J. Mackey.

\section{References}

Brodey, R. S., McDonough, S. K., Frye, F. L., and Hardy, W. D. (1970). Epidemiology of feline leukemia (lymphosarcoma). In Comparative Leukemia Research, 1969: Proceedings of the IVth International Symposium (Bibliotheca Haematologica, No. 36), edited by R. M. Dutcher, pp. 333-342. Karger, Basle and New York.

Essex, M., Klein, G., Snyder, S. P., and Harrold, J. B. (1971). Correlation between humeral antibody and regression of tumours induced by feline sarcoma virus. Nature (Lond.), 233, 195-196.

Gardner, M. B. (1971). Current information on feline and canine cancers and relationship or lack of relationship to human cancer. J. nat. Cancer Inst., 46, 281-290.

Huebner, R. J., Todaro, G. J., Sarma, P., Hartley, J. W., Freeman, A. E., Peters, R. L., Whitmire, C. E., Meier, H., and Gilden, R. V. (1970). 'Switched off' vertically transmitted C-type RNA tumour viruses as determinants of spontaneous and induced cancer: a new hypothesis of viral carcinogenesis. In Defectiveness, Rescue and Stimulation of Oncogenic I'iruses, pp. 33-57. Éditions du Centre National de la Recherche Scientifique, Paris.

Jarrett, W., Mackey, L. J., Jarrett, O., and Laird, H. M. (1972). Feline leukaemia infection: the spectrum of associated disease and its relevance to the pathogenesis and immunology of leukaemia. In Comparative Leukaemia Research: Proceedings of the Vth International Symposium 1971. (Bibliotheca Haematologica.) Karger, Basle and New York.

Mackey, L. J. and Jarrett W. (1972). The pathogenesis of lymphoid neoplasia in cats and its relationship to immunological cell traftic routes. J. nat. Cancer Inst., in press.

Mackey, L. J., Jarrett, W., Jarrett, O., and Laird, H. M. (1972). An experimentalstudy of virus leukaemia in cats. J. nat. Cancer Inst., in press.

Noronha, F. de, Post, J. E., Norcross, N. L., and Rickard, C. G. (1972). Induction of group-specific interspecies antibody in a cat by immunisation with disrupted feline leukaemia virus. Nature (new Biol.), 235, 14-15.

Rickard, C. G., Post, J. E., Noronha, F. de, and Barr, L. M. (1969). A transmissible virus-induced lymphocytic leukemia of the cat. J. nat. Cancer Inst., 42, 987-1014.

Riggs, J. L. (1971). An immunofluorescent test for feline leukemia and sarcoma virus antigens and antibodies. J. Amer. vet. med. Ass., 158, 1085-1087. 